\title{
AISI 4140 Çelik Yüzeyinde Termoreaktif Difüzyon Yöntemiyle Elde Edilen TiC Kaplamasının Mikroyapı Özelliklerinin İncelenmesi
}

\author{
Soner BUYTOZ ${ }^{*}$, Burhan YILMAZ ${ }^{2}$ \\ ${ }^{1}$ Metalurji ve Malzeme Mühendisliği, Teknoloji Fakültesi, Fırat Üniversitesi, Elazı ̌̆, Türkiye \\ ${ }^{2}$ Metalurji ve Malzeme Mühendisliği, Teknoloji Fakültesi, Fırat Üniversitesi, Elazığ, Türkiye \\ *1 sbuytoz@gmail.com, ${ }^{2}$ burhanyilmaz2223@gmail.com
}

Öz: Bu çalışmada AISI 4140 çeliğinin yüzeyi ferro-titanyum (FeTi) tozuyla kaplanmıştır. Kaplamalar, üç farklı sıcaklıkta (900 ${ }^{\circ} \mathrm{C}, 1000{ }^{\circ} \mathrm{C}$ ve $1100{ }^{\circ} \mathrm{C}$ ) ve üç farklı sürede (1 saat, 2 saat ve 3 ) paket sementasyon yöntemiyle bir termo-reaktif difüzyon (TRD) işlemi kullanılarak gerçekleştirmiştir. Kaplamaların yapısal ve mekanik özellikleri karşılaştırılmıştır. Bu amaçla, oluşan fazların tipleri, mikroyapıları, mikro sertlikleri incelenmiştir. XRD analizi sonucunda kaplama tabakalarında $\alpha$-Fe ve TiC fazları tespit edildi. . Kaplamaların kalınlığı 3.04-11.70 $\mu \mathrm{m}$ ve sertlik 1089-2335 HV değerleri elde edildi. Kaplamaların Ti içeren faz bileşenleri, artan kaplama sıcaklıkları ile arttı.

Anahtar kelimeler: Kaplama, mikroyapı, termoreaktif difüzyon, sertlik.

\section{Investigation of microstrucutural properties of TiC coating obtained by termoreactive diffusion process on AISI4140 steel}

\begin{abstract}
In the current study, the surface of AISI 4140 steel was coated with ferro-titanium (FeTi) powder. The coatings were performed using a thermo-reactive diffusion (TRD) treatment by the pack cementation method at three different temperatures $\left(900{ }^{\circ} \mathrm{C}, 1000^{\circ} \mathrm{C}\right.$, and $\left.1100^{\circ} \mathrm{C}\right)$ and three different durations $(1 \mathrm{~h}, 2 \mathrm{~h}$, and $3 \mathrm{~h})$. The structural and mechanical characteristics of the coatings were compared between the treatment groups. For this purpose, the types, microstructures and microhardness of the phases were investigated. XRD analysis revealed $\alpha-\mathrm{Fe}$ and TiC phases in the coating layers. Thickness of the coatings were $3.04-11.70 \mu \mathrm{m}$ and hardness, 1089 - $2335 \mathrm{HV}$ values were obtained. The phase components containing Ti of the coatings increased with increasing coating temperatures.
\end{abstract}

Key words: Coating, microstructure, termoreactive diffusion, hardness.

\section{Giriş}

Titanyum karbür (TiC), yüksek erime noktası, sertliği, mukavemeti ve mükemmel aşınma direncinin yanı sıra olağanüstü kimyasal kararlılığı nedeniyle, yüzey özelliklerini geliştirmek için bir kaplama malzemesi olarak yaygın bir şekilde kullanılmaktadır [1-3]. TiC kaplama genel olarak, fiziksel buhar biriktirme (PVD) ve kimyasal buhar biriktirme (CVD) yöntemleriyle üretilerek kullanıma sunulmuştur. Son yıllarda, termoreaktif difüzyon işlemi (TRD), uygulama kolaylığı, asgari ekipman gereklilikleri ve maliyet verimliliği bakımından, hem PVD hem de CVD işlemlerine göre daha çok tercih edilen bir yöntem olmuştur [4-7].

TRD kaplama yöntemi aslında bir termokimyasal işlemdir. Ancak geleneksel termokimyasal işlemlerden biraz farklıdır. Kaplama yönteminde çelik altlıktaki karbon ve azot yüksek sıcaklıkta $\left(800-1250{ }^{\circ} \mathrm{C}\right)$ yüzeye difüze olarak titanyum, vanadyum, niobyum, tantalyum, krom, molibden ya da tungsten gibi kuvvetli karbür ve nitrür yapıcı refrakter geçiş metalleri ile birleşerek çelik yüzeyinde yoğun, gözeneksiz ve ana metale sıkı bir şekilde bağlanmış kaplama tabakası oluşturur. Geleneksel metotların aksine oluşan kaplama tabakası altlık yüzeyinde gelişir. Altlık malzeme ile kaplama tabakası arasında belirgin bir sınır vardır. Ancak, işlem yüksek sıcaklıkta gerçekleştirildiği için karbür oluşturucu elementlerin ana metal içine difüzyonu söz konusudur. Bu da metalurjik olarak bağlı bir yapı oluşturmaktadır [8].Yalnız termoreaktif difüzyon işleminin olabilmesi için çelik esaslı malzemenin $\mathrm{C}$ içeriğinin en az \%0,3 veya daha büyük olması önemlidir [9].

$\mathrm{Bu}$ nedenle çalışmanın amacı, diğer endüstriyel uygulamalarda kullanımlarını genişletmek ve olası uygulamaların daha iyi anlaşılmasını sağlamak amacıyla, TRD yöntemiyle AISI 4140 çelik alt tabaka üzerinde bir titanyum karbür tabakası oluşturarak, mikroyapısal ve mekanik özelliklerini belirlemektir.

\footnotetext{
${ }^{*}$ Sorumlu yazar: sbuytoz@gmail.com. Yazarların ORCID Numarası: ${ }^{1}$ 0000-0003-1509-8648
} 


\section{Deneysel Çalışma}

Bu çalışmada, AISI 4140 malzeme yüzeyi termoreaktif difüzyon (TRD) tekniği kullanılarak Ferro titanyum (FeTi) ile kaplandı. Alt tabaka malzemesinin kimyasal bileşimi ağırlıça \%0.394C, \%0.279Si, \%1.021Cr, $\% 0.74 \mathrm{Mn}$ ve $\% 96.793 \mathrm{Fe}$ olmakla birlikte, kaplamada kullanılan tozun kimyasal bileşimi ağırlıça \%54.92Fe ve \%45.08Ti' dur. FeTi tozunun SEM görüntüsü ve EDX difragtoramı Şekil 1' de verilmiştir. Kaplama işleminden önce 10x10x10 mm3 ebatlarında kesilen numunelerin tüm yüzeyleri oksit ve yağ kalıntılarından arındırmak için ultrasonik olarak aseton ve etanol banyosunda temizlendikten sonra, SiC zımpara kağıtlarıyla parlatıldı ve nihai parlatma işlemiyle cilalandı. Kaplama işlemi için hazırlanan numuneler, Şekil 2' de görülen AISI 304 paslanmaz çelik pota içinde, $\% 45 \mathrm{FeTi}, \% 45 \mathrm{Al}_{2} \mathrm{O}_{3}$ ve $\% 10 \mathrm{NH}_{4} \mathrm{CI}$ ortamına gömüldü. Karşım tozlarının birbirleriyle sinterlenmesini önlemek için inert dolgu malzemesi ve aktivatör kullanıld1. İnert malzeme olarak Al2O3, aktivatör malzeme olarak ise $\mathrm{NH} 4 \mathrm{Cl}$ malzemesi kullanıld. Kaplama işlemi parametreleri $900{ }^{\circ} \mathrm{C}, 1000{ }^{\circ} \mathrm{C}$ ve $1100^{\circ} \mathrm{C}$ lik sıcaklıklarda 1,2 ve 3 saat seçildi. İşlem sonrası fırından çıkarılan sıcak potalar suda hızlı soğutuldu. Son olarak, potanın ağzı açılarak numuneler çıkarılıp yine hızlı bir şekilde suda soğutulma işlemine tabi tutuldu. Numuneler çıkarılarak, kaynar suda temizlendikten sonra etanol banyosunda ultrasonik olarak temizlendi.

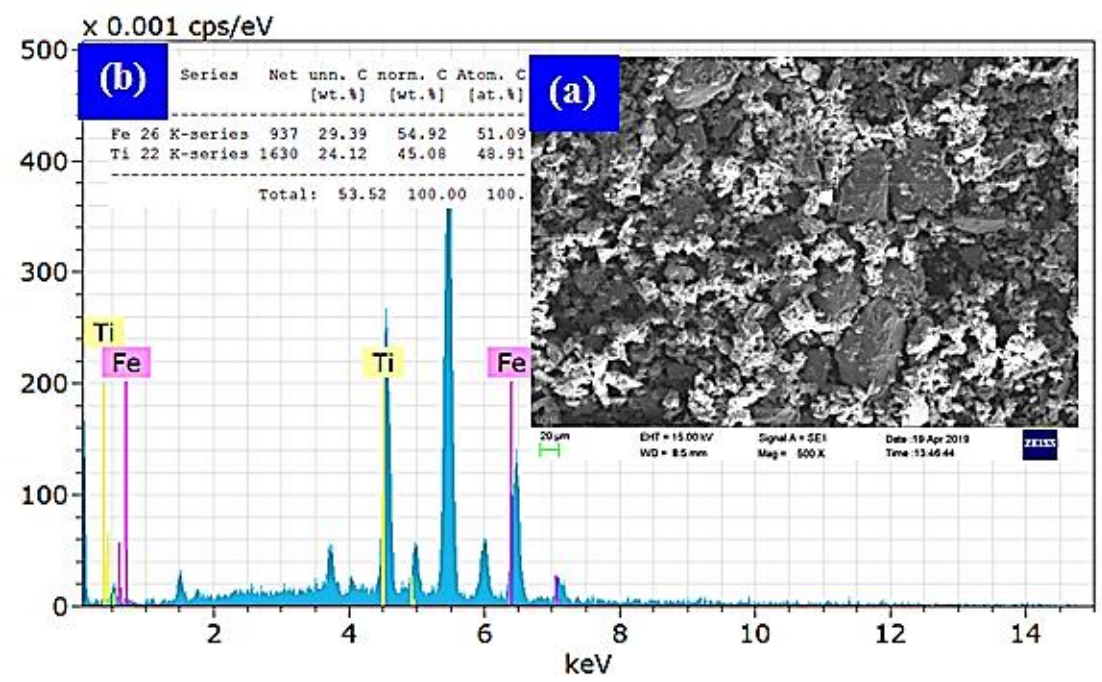

Şekil 1. FeTi tozunun (a) SEM görünüşü ve (b) EDS verisi

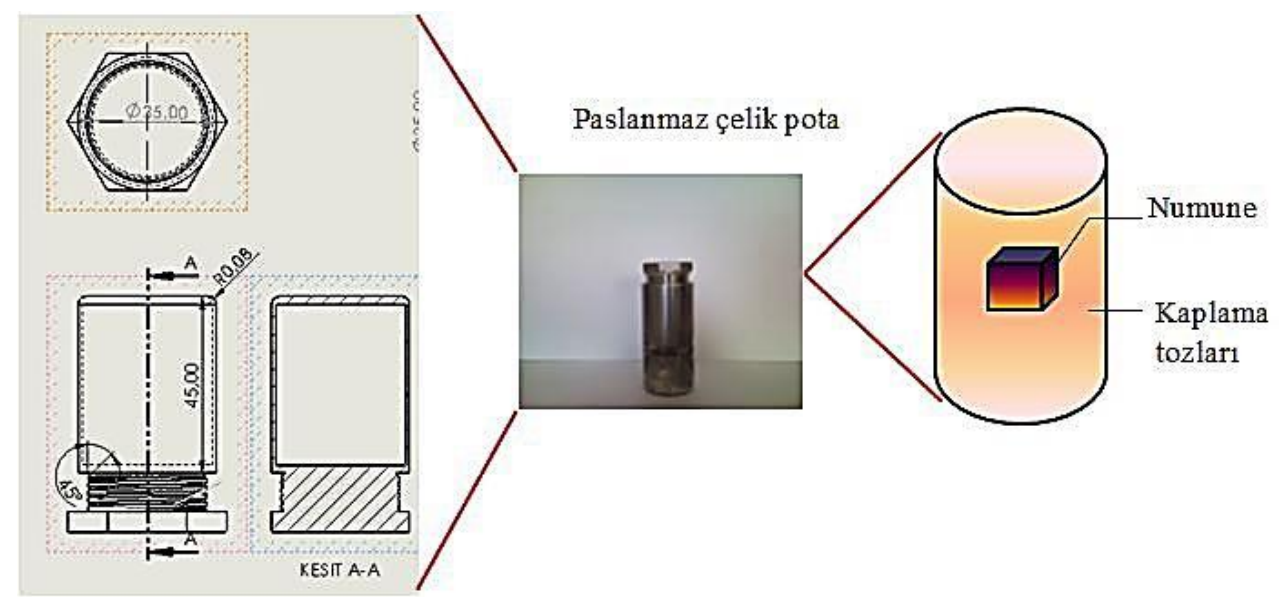

Şekil 2. AISI304 paslanmaz çelik potanın makrofotoğrafı ve deney numunesinin şematiği

Termo Reaktif Difüzyon yöntemi ile kaplanan numuneler standart metalografik işlemlerden geçirilerek 2402500 mesh SiC kağıtlarla zımparalama ve 3 ve $1 \mu \mathrm{m}$ elmas süspansiyonlar parlatma işlemi yapıldı. Parlatılan 
numunelerin optik ve SEM incelemeleri için, \% 5'lik nital çözeltisinde kimyasal daldırma yöntemiyle dağlama işlemine tabi tutuldu. Optik incelemelerde, Clemex görüntü analiz sistemi ve Nikon EclipseMA-200 optik metal mikroskobu kullanıldı. Kaplama yüzeyi ve kesit morfolojisi taramalı elektron mikroskobu (SEM JEOL JSM-5600) ile incelendi. Elementel dağılım, X-ışını spektroskopisi (EDS) ile karakterize edildi. Kaplamada oluşan fazlar, yüksek çözünürlüklü Bruker AXS D8 Advance model X-ışını kırınımı (XRD) analizi kullanılarak belirlendi. X

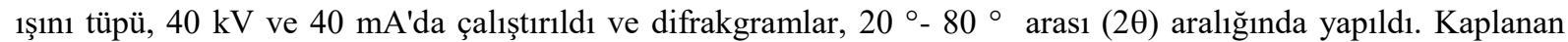
malzemenin mikrosertlik değerleri Durascan20 struers marka mikrosertlik cihazıyla, 50 gr yük altında 10 saniye yük uygulayarak, kaplamanın farklı bölgelerinden en az 5 değer ölçüm alınıp aritmetik ortalaması kaydedildi.

\section{Sonuçlar ve Tartışma}

TRD yöntemiyle $900^{\circ} \mathrm{C}$ 'de 1,2 ve 3 saat süreyle yapılan kaplanmış numunenin yan kesit yüzey morfolojisinin SEM ve EDS görselleri Şekil 3 ve Şekil 4' de verilmiştir. Şekil 3(a)' da, 1 saat süreyle termoreaktif işleme tabi tutulan numunenin yan kesit yüzey morfolojisi ve EDS analizi giydirilmiş bir durumda görülmektedir. Şekil 3'den, kaplama tabakası AISI4140 malzemesinin yüzeyinde bir katman şeklinde \%85.18 ăg. Ti ve \%13.55 ağ. Fe ağırlık oranlarında, sis bulutuna benzer bir görünümle katman oluşturduğu tespit edilmiştir. Şekil 3(b)' de aynı numunenin EDS haritalaması verilmiştir. Yeşil renkle görülen Ti elementinin üst katman boyunca homojen ve yoğun bir dağılım sergilediği anlaşılmaktadır.

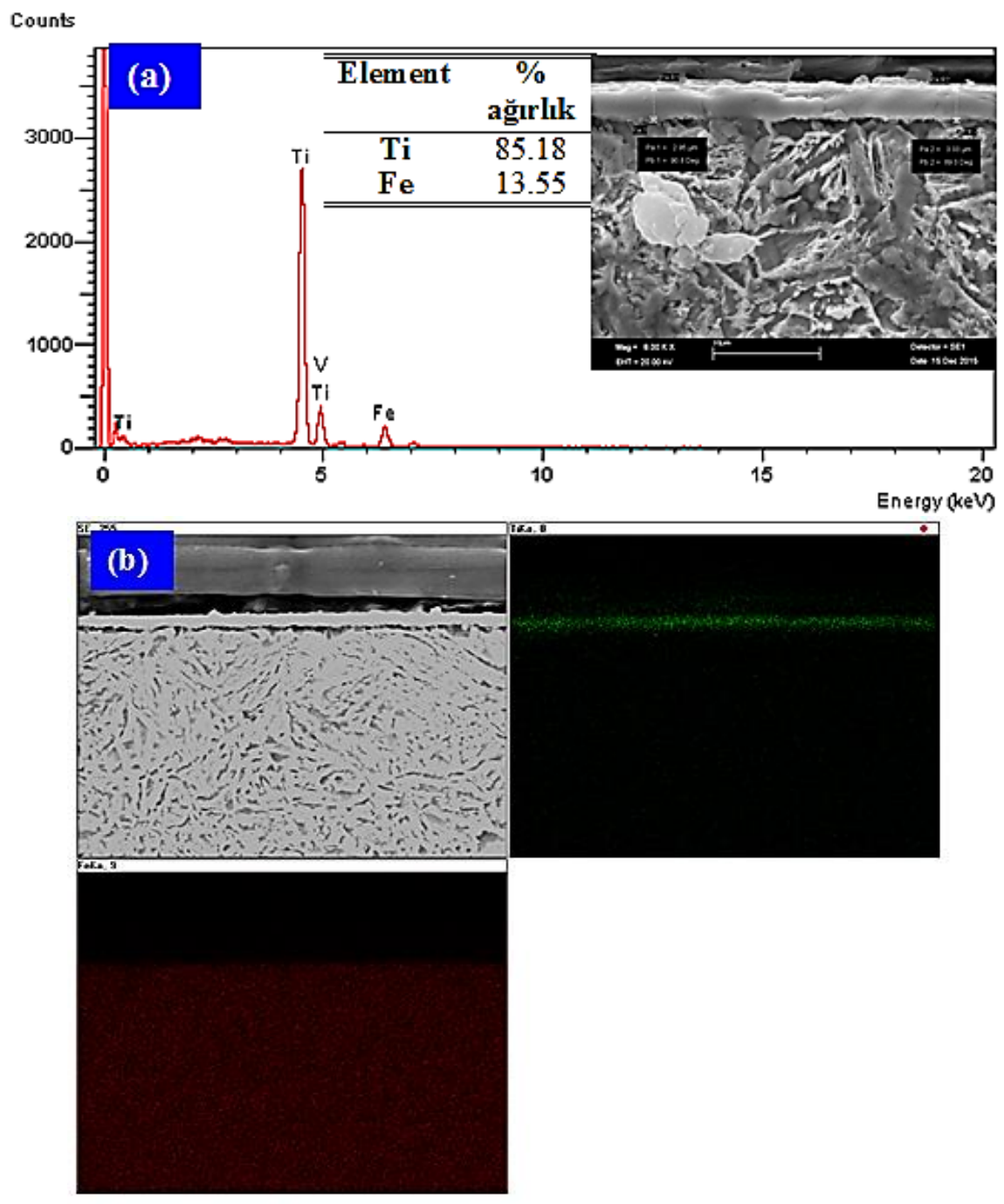

Şekil 3. $900{ }^{\circ} \mathrm{C}$ 'de 1 saatte üretilen kaplama malzemesinin (a) SEM ve EDS analizi, (b) EDS haritalaması 
Kaplama süresinin artmasıyla kaplama tabakasında Ti miktarının çok az arttığı ve Fe oranının bunun paralelinde azaldığı Şekil 4(a) ve Şekil 4(b)’ de gösterilmiştir. Artan süre, difüzyon mekanizmasının etkinliğini arttırıp kaplama tozları içindeki Ti atomlarının numune yüzeyine artarak difüze olmasına olanak sağlamıştır. Ti esaslı kaplama dışa doğru bir büyüme gerçekleştirmiştir. Bunun sonucunda kaplama/alt tabaka ara yüzü düz bir hat sergilemiştir [10,11].900 ${ }^{\circ} \mathrm{C}$ sıcaklıkta üretilen numuneler için, termoreaktif difüzyon kaplama işlem süresinin 1 saatten 2 ve 3 saate değişmesi, kaplama tabakasının ara yüzey düzgünlüğünü daha da belirginleştirdiği Şekil 4' den de görülebilir.
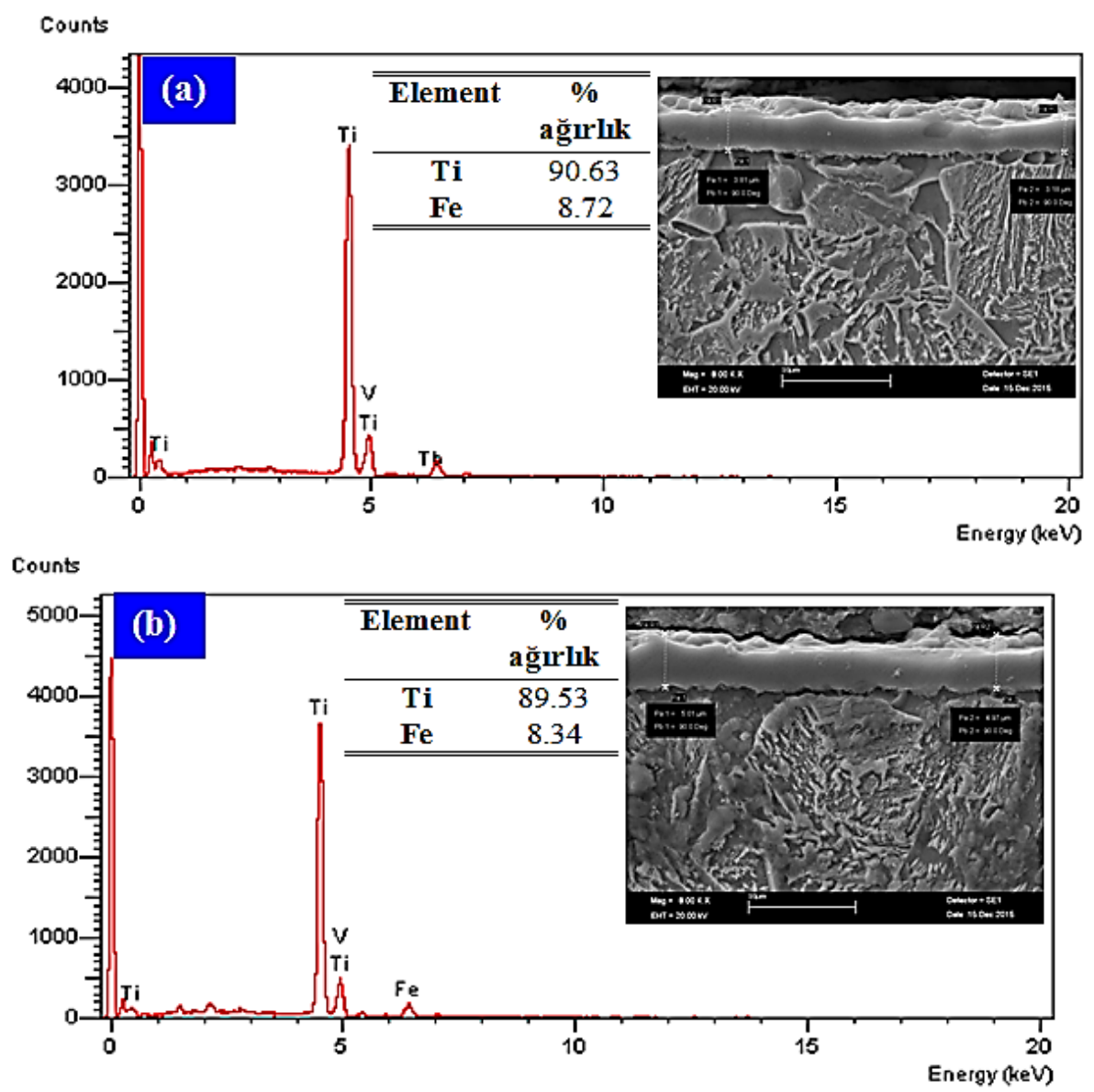

Şekil 4. $900{ }^{\circ} \mathrm{C}$ için (a) 2 saat ve (b) 3 saat işlem sürelerinde üretilen kaplama malzemelerinin SEM ve EDS analizleri

Termoreaktif difüzyon işlemiyle $1000^{\circ} \mathrm{C}$ ve $1100^{\circ} \mathrm{C}^{\prime}$ de üç farklı süreyle yapılan kaplama işlemi sonucu elde edilen SEM mikroyapıları Şekil 5' de verilmiştir. Şekil 5' den de görüldüğü üzere, kaplama tabakaları Şekil 3 ve Şekil 4' de verilen numunenin mikroyapılarına göre daha düzgün ve kaplama alt tabaka arayüz bölgesi daha yumuşak ve homojen bir geçiş olmuştur. Ayrıca sıcaklığın arttırılmasıyla kaplama tabakasında \% Ti element miktarının da arttığı EDS sonuçlarından tespit edilmiştir (Tablo 1). En iyi yan kesit yüzey morfolojisi sıcaklığın $1100{ }^{\circ} \mathrm{C}^{\prime}$ ye çıkarılarak 3 saat sonrası elde edilen numunede kaydedilmiştir. Geçiş/ alt tabaka yüzey düzgünlüğü, tüm numune ve işlem parametreleri için en ideal şart olarak görülmektedir.

Sıcaklık ve işlem süresi arttığında yüzeye geçen element miktarı, difüzyon için gerekli süreyi yeterince bulduğundan daha çok geçiş sağladı. Bunun sonucunda yüzey tabakası daha düzgün ve geçiş/ alt tabaka arayüzü, diğer kaplama yöntemlerine göre daha homojen bir görünüm sergiledi [12,13]. Tablo 1' e göre, $1000{ }^{\circ} \mathrm{C}$ için 1 saat işlemle yapılan kaplama yönteminde, kaplama tabakasında \%92.83 ağırlık oranında Ti ve \%5.91 ağ. Fe elementi ihtiva ederken, aynı sıcaklık ve 3 saat süreyle elde edilen katmanda bu oran $\% 97.37 \mathrm{ağ}$. Ti, \%2.63 ağ. Fe elementi kaydedildi. $1100^{\circ} \mathrm{C}$ sıcaklık için EDS spektrumundan alınan elementel ağırlık oranları, \%96.63 ağ. Ti, 
\%2.81 ağ. Fe elementleri 1 saat kaplama süresinde kaydedilirken, bu değer 3 saat süreye arttırılıp elde edilen kaplama tabakasında \%97.70 ăg. Ti ve \% 2.30 ağ. Fe ölçümleri alındı.

FeTi kaplamalarıyla elde edilen katmanların XRD analizleri Şekil 6'da verilmiştir. Numuneler üzerinde yapılan XRD incelemesine göre numuneler üzerinde hegzagonal yapıda TiC baskın faz (PDF No 06-0696) olarak belirlenmiştir. İkincil faz olarak kübik $\alpha$-Fe fazı (PDF No 72-2496) oluşmakla birlikte, prosesin işlem sıcaklığı ve sürelerinin artmasına göre $\alpha$-Fe fazında azalma, fakat TiC fazının kararlığında ise artma görülmüştür. Kübik $\alpha$-Fe fazı $a=2,8664, b=2,86640$ ve $c=2,86640$ kafes parametreleriyle oluşum gösterirken, hegzagonal TiC fazı; $a=6,11500, b=6,11500$ ve $c=14,90000$ kafes parametrelerinde meydana gelmiştir. Reaksiyon bileşimi Fe-Ti denge faz diyagramına göre ikincil fazlar Fe veya Fe2Ti fazlarının meydana gelebilme olasılığıdır [14]. Ancak Ti elementi, $\alpha$-Fe deki katı çözünürlüğünü azaltan TiC oluşturma ihtimali oldukça yüksektir [15]. İncelenen numunelerin XRD değerlerinden, en düşük TiC fazı kararlılı̆̆ $900{ }^{\circ} \mathrm{C}$ 'de 1 saatte üretilen numunede en yüksek kararlılık ise $1100^{\circ} \mathrm{C}^{\prime}$ de 3 saatte üretilen numunede görülmüştür.
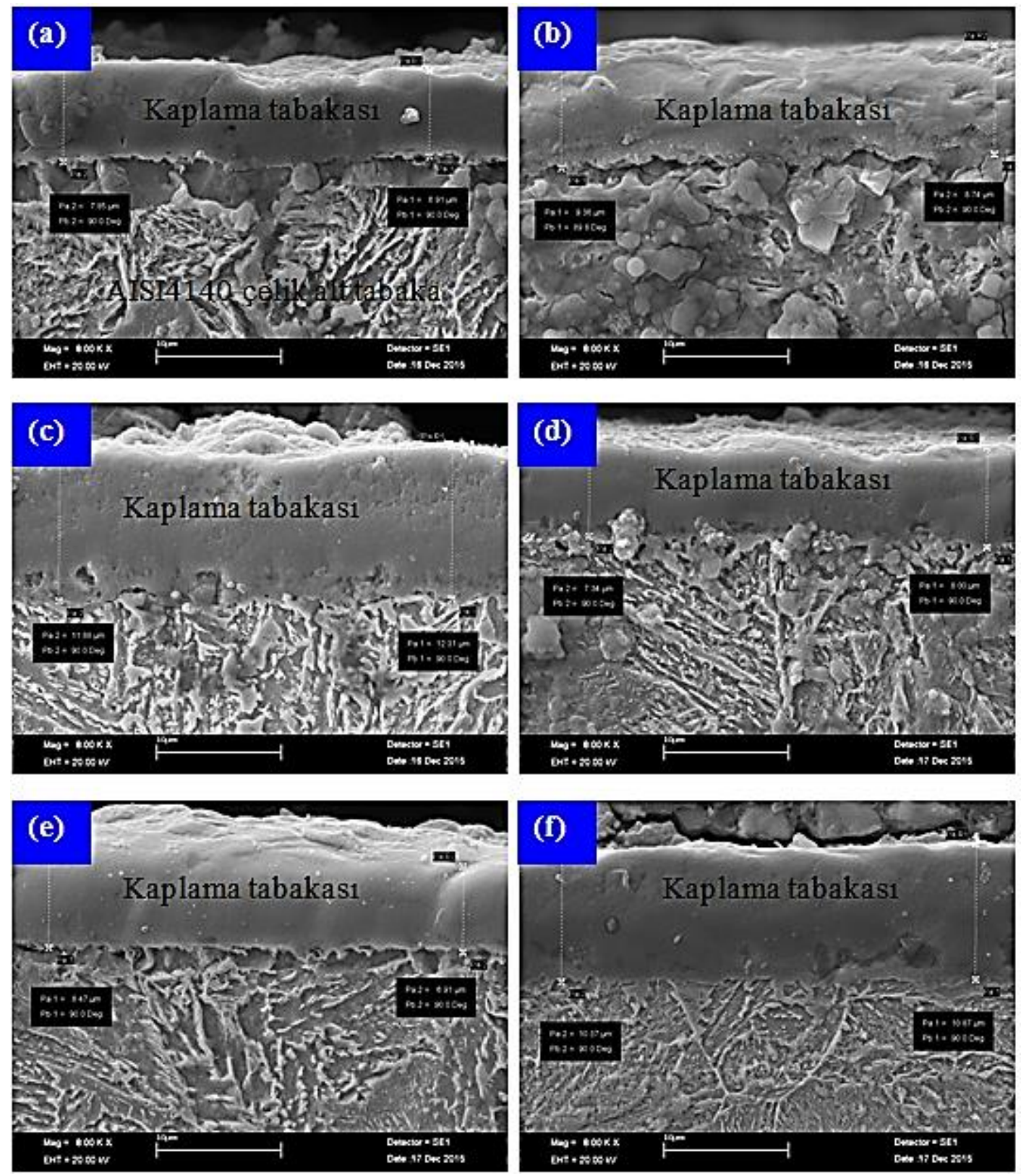

Şekil 5. $1000^{\circ} \mathrm{C}$ ve $1100^{\circ} \mathrm{C}$ için TRD yöntemiyle kaplanan numunelerin yankesit SEM görünüşleri 
Tablo 1. $1000{ }^{\circ} \mathrm{C}$ ve $1100^{\circ} \mathrm{C}$ için EDS analiz sonuçları

\begin{tabular}{lcc}
\hline \hline Numune & \multicolumn{2}{c}{ Element (\% ağıllık) } \\
\cline { 2 - 3 } & $\mathrm{Ti}$ & $\mathrm{Fe}$ \\
\hline $1000^{\circ} \mathrm{C}$ için 1 saat süreli numune & 92.83 & 6.91 \\
$1000^{\circ} \mathrm{C}$ çị 2 saat süreli numune & 94.48 & 4.96 \\
$1000^{\circ} \mathrm{C}$ çin 3 saat süreli numune & 97.37 & 2.63 \\
$1100^{\circ} \mathrm{C}$ için 1 saat süreli numune & 96.63 & 2.81 \\
$1100^{\circ} \mathrm{C}$ için 2 saat süreli numune & 97.14 & 2.46 \\
$1100^{\circ} \mathrm{C}$ için 3 saat süreli numune & 97.70 & 2.30 \\
\hline \hline
\end{tabular}

Şekil 7' de termoreaktif difüzyonda sıcaklık ve süre değişiminin kaplama tabakasının sertlik ve kaplama kalınlığına etkisi grafiksel olarak verilmiştir. Şekil 7' e göre, $900{ }^{\circ} \mathrm{C}$ sıcaklık ve 1 saat kaplama süresinde elde edilen katman kalınlığı ortalama 3,04 $\mu$ m ölçülürken sürenin sırayla 2 ve 3 saate yükseltilmesiyle kaplama kalınlığında da sırayla 3.66 ve $4,42 \mu \mathrm{m}$ değerleri belirlenmiştir. Sıcaklık $1000^{\circ} \mathrm{C}$ ' ye yükseltildiğinde elde edilen kaplama kalınlı̆̆ $900^{\circ} \mathrm{C}$ ' ye göre iki kattan daha fazla değerler elde edilmiştir. Ti elementinin termoreaktif difüzyon işlemiyle alt tabaka yüzeyinde katman şeklinde birikip kaplama oluşturması için yeterli sıcaklığa ulaştı̆̆ının sonucu çıkarılabilir [16,17]. Kaplama kalınlıkları 7,16 $\mu \mathrm{m}$ ile $11,70 \mu \mathrm{m}$ arasında tespit edilmiştir. Sıcaklık $1100{ }^{\circ} \mathrm{C}$ ' deki kaplama kalınlıkları $1000{ }^{\circ} \mathrm{C}$ ' de üretilen kaplamalara oldukça yakın kaydedilmiştir. Kaplama kalınlığının işlem süresine oldukça bağlı olduğu literatürde bildirilmiştir [18].
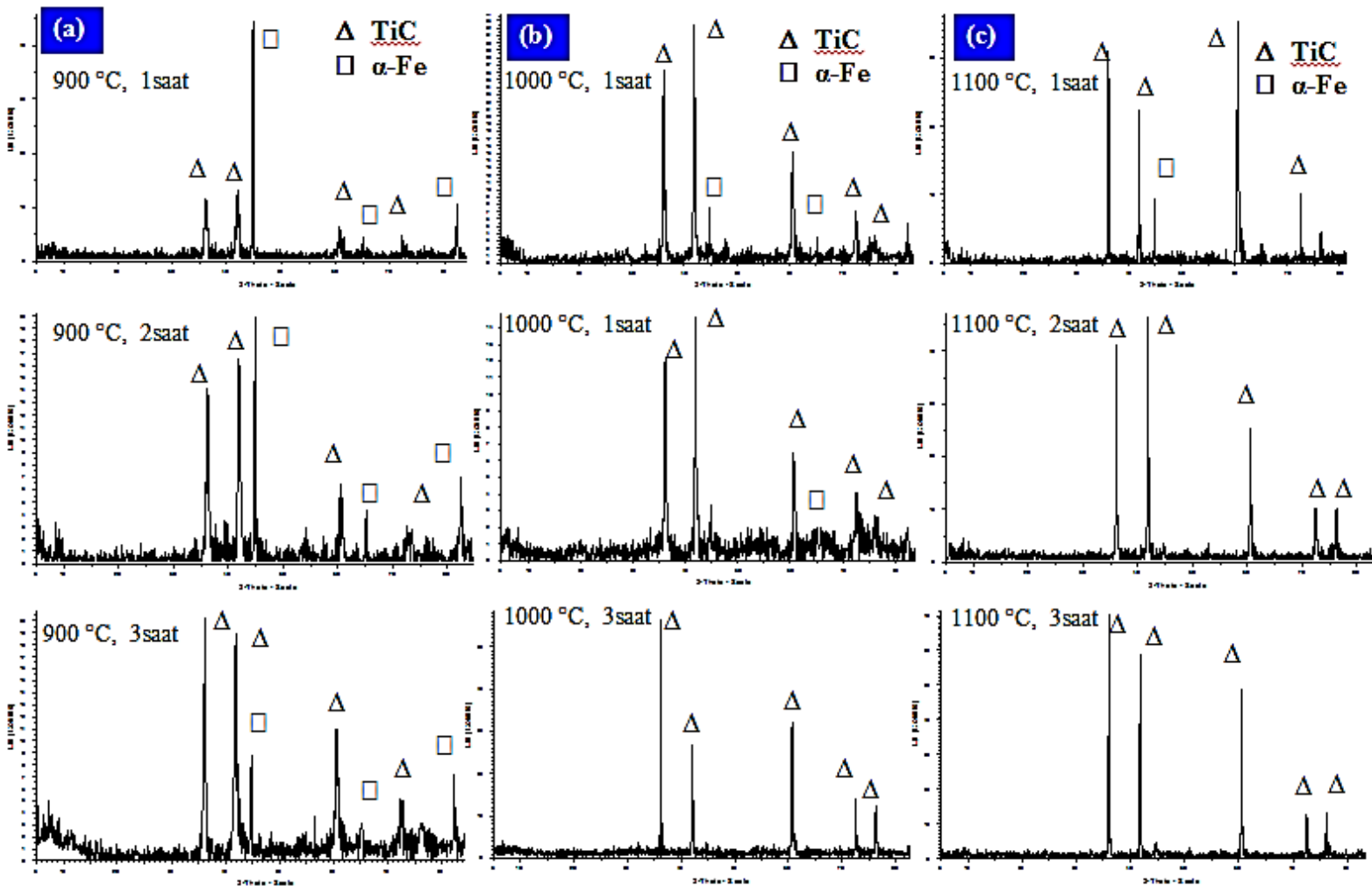

Şekil 6. (a) $900{ }^{\circ} \mathrm{C}$ ve (b) $1000{ }^{\circ} \mathrm{C}$ ve (c) $1100^{\circ} \mathrm{C}$ ' de 1,2 ve 3 saat süreyle kaplanan numunelerin XRD analizleri

Kaplanan numunelerin işlem sıcaklık ve süresine bağlı olarak sertlik değişimleri aynı zamanda Şekil 7' de verilmiştir. Sertlik değerleri kaplama ve alt tabaka malzemesinin farklı bölgelerinden 5 adet ölçüm alınarak, bu ölçümlerin aritmetik ortalamaları alınmıştır. AISI4140 alt tabaka malzemesinin sertlik değeri $250 \mathrm{HV}$ iken, termoreaktif difüzyon yöntemiyle yapılan kaplamaların sertlik değerleri en az 4 kat daha yüksek kaydedilmiştir. $\mathrm{Bu}$ oran işlem süresi ve sıcaklığ 1 arttıkça, artmıştır. $900^{\circ} \mathrm{C}^{\prime}$ de 1,2 ve 3 saat üretim parametrelerinde elde edilen sertlik değerleri sırasıyla $1089 \mathrm{HV}, 1130 \mathrm{HV}$ ve $1392 \mathrm{HV}$ iken, sıcaklık $1000^{\circ} \mathrm{C}$ ' ye çıkarıldığında mikrosertlik 
değerleri de $900{ }^{\circ} \mathrm{C}$ ' de elde edilen numuneye göre oldukça bir artış göstermiştir. $1000{ }^{\circ} \mathrm{C}$ ' de elde edilen numuneler için sertlik değerleri $1168 \mathrm{HV}, 1345 \mathrm{HV}$ ve $1750 \mathrm{HV}$ ' dir. En yüksek mikrosertlik değerleri $1100{ }^{\circ} \mathrm{C}$ sıcaklıkta üretilen kaplama tabakalarından alınmıştır. Sertlik 1 saat, 2 saat ve 3 saat sürelerle elde edilen $1100{ }^{\circ} \mathrm{C}^{\prime}$ deki numuneler için $1541 \mathrm{HV}, 1716 \mathrm{HV}$ ve $2335 \mathrm{HV}$ ' dir. Hem sıcaklık, hem de işlem süreleri bakımından kıyaslandığında, artan sıcaklık ve artan sürelerde kaplama tabakalarının mikrosertlik değerleri de arttığı tespit edilmiştir $[19,20]$.

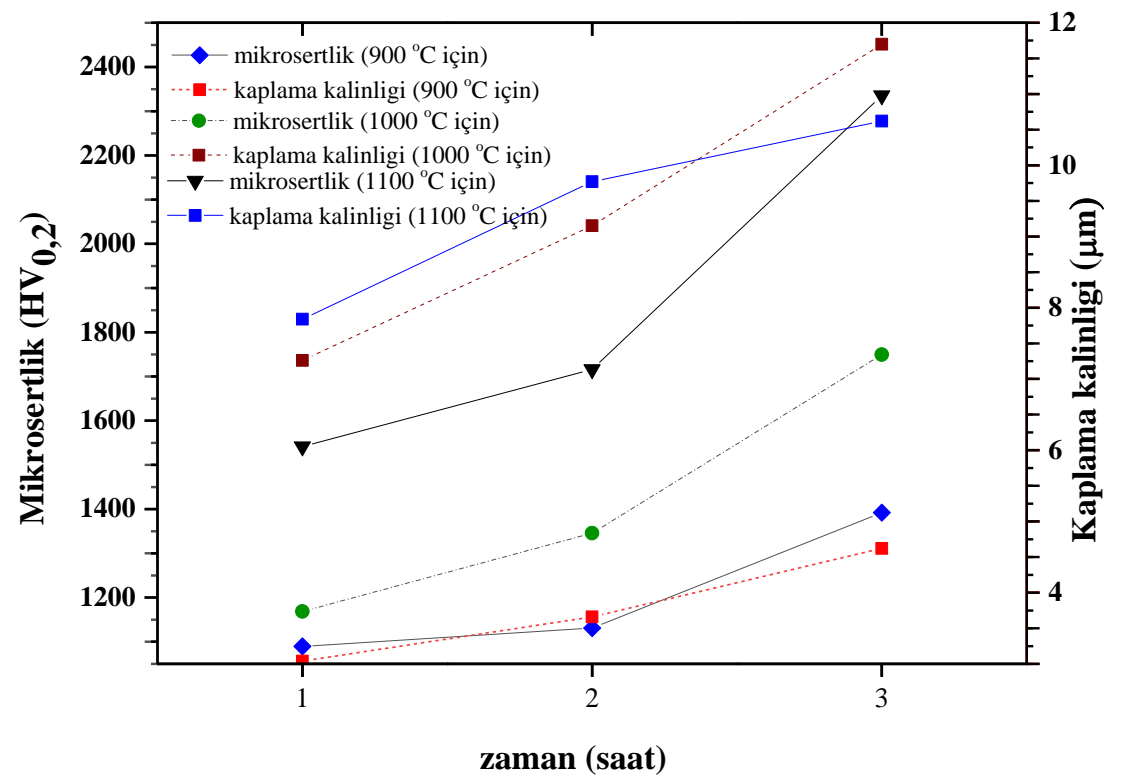

Şekil 7. Numunelerin sıcaklık ve süreye bağlı olarak kaplama kalınlığı ve mikrosertliklerinin değişimi

\section{Genel Sonuçlar}

Çalışmada AISI 4140 çelik malzeme, $900{ }^{\circ} \mathrm{C}, 1000{ }^{\circ} \mathrm{C}$ ve $1100{ }^{\circ} \mathrm{C}$ sicaklık ve 1 saat, 2 saat ve 3 saat sürelerinde termoreaktif difüzyon yöntemiyle FeTi tozları başarılı bir şekilde kaplanmıştır. Kaplama tabakalarında birincil faz olarak hegzagonal yapılı TiC baskın fazlarla birlikte, ikincil faz kübik yapılı $\alpha$-Fe fazı belirlenmiştir. Sıcaklık ve sürenin artmasına bağlı olarak, birincil TiC miktarının arttığı, tam tersi $\alpha$-Fe azaldığı tespit edilmiştir. Tüm üretim parametrelerinde $3.04 \mu \mathrm{m}$ ile $11.70 \mu \mathrm{m}$ arasında bir Ti esaslı kaplama tabakası elde edilmiştir. Kaplama tabakasının mikrosertlik değerleri alt tabakasına göre oldukça yüksek değerler kaydedilmiştir. Sıcaklık ve sürenin artışına paralel olarak, sertlik değerleri de artmıştır. En yüksek sertlik değeri 2335 HV olarak ölçülmüştür.

\section{Kaynaklar}

[1] Stüber M, Leiste H, Ulrich S, Holleck H, Schild D. Microstructure and properties of low friction TiC-C nanocomposite coatings deposited by magnetron sputtering. Surf Coat Technol 2002; 150: 218-226.

[2] $\mathrm{Hu} \mathrm{Y,} \mathrm{Li} \mathrm{L,} \mathrm{Cai} \mathrm{X,} \mathrm{Chen} \mathrm{Q,} \mathrm{Chu} \mathrm{P.K.} \mathrm{Mechanical} \mathrm{and} \mathrm{tribological} \mathrm{properties} \mathrm{of} \mathrm{TiC/amorphous} \mathrm{hydrogenated} \mathrm{carbon}$ composite coatings fabricated by DC magnetron sputtering with and without sample bias. Diam Relat Mater 2007; 16(1): 181-186.

[3] El Mel A.A, Gautron E, Christien F, Angleraud B, Tessier P.Y. Titanium carbide/carbon nanocomposite hard coatings: a comparative study between various chemical analysis tools. Surf Coat Technol 2014; 256: 41-46.

[4] Arai T, Moriyama S. Growth behavior of vanadium carbide coatings on steel substrates by a salt bath immersion coating process. Thin Solid Films 1994; 249 (1): 54-61.

[5] Dong W, Xu L, Wen J, Lin Q, Wang Z. Galling mechanism in metal forming process with TRD coated die against advanced high strength steel sheet. Procedia Engineering 2017; 207: 2233-2238.

[6] Zhang K, Wen M, Cheng G, Li X, Meng Q.N, Lian J.S. Reactive magnetron sputtering deposition and characterization of niobium carbide films. Vacuum 2014; 99: 233-241. 
[7] Aghaie-Khafri M, Fazlalipour F. Vanadium carbide coatings on die steel deposited by the thermo-reactive diffusion technique. J Phys Chem Solids2008; 69: 2465-2470.

[8] Chaliampalias D, Vourlias G, Pavlidou E, Skolianos S, Chrissafis K, Stergioudis G. Comparative examination of the microstructure and high temperature oxidation performance of NiCrBSi flame sprayed and pack cementation coatings. Appl Surf Sci 2009; 255(6): 3605-3612.

[9] Oliveira C.K.N, Benassi C.L, Casteletti L.C. Evaluation of hard coatings obtained on AISI D2 steel by thermo-reactive deposition treatment. Surf Coat Technol 2006; 201: 1880-1885.

[10] Fan X.S, Yang Z.G, Xia Z.X, Zhang C, Che H.Q. The microstructure evolution of VC coatings on AISI H13 and 9Cr18 steel by thermo-reactive deposition process. J Alloys Compd 2010; 505: 15-18.

[11] Ghadi A, Soltanieh M, Saghafian H, Yang Z.G. Investigation of chromium and vanadium carbide composite coatings on CK45 steel by Thermal Reactive Diffusion. Surf Coat Technol 2016; 289: 1-10.

[12] Chen Y.M, Yu G.P, Huang J.H. Role of process parameters in the texture evolution of TiN films deposited by hollow cathode discharge ion plating. Surf Coat Technol 2001; 141: 156-163.

[13] Fan X.S, Yang Z.G, Zhang C, Zhang Y.D, Che H.Q. Evaluation of vanadium carbide coatings on AISI H13 obtained by thermo-reactive deposition/diffusion technique. Surf Coat Technol 2010; 205: 641-646.

[14] Zhang J, Li S, Lu C, Sun C, Huang M. Anti-wear titanium carbide coating on low-carbon steel by thermo-reactive diffusion. Surf Coat Technol 2019; 364(25): 265-272.

[15] Akamatsu S, Hasebe M, Senuma T, Matsumura Y, Kisue O. Thermodynamic calculation of solute carbon and nitrogen in $\mathrm{Nb}$ and Ti added extra-low carbon steels. ISIJ Int 1994; 34: 9-16.

[16] Kurt B, Sinoplu O, Carboga C, Demirel B. The investigation and growth kinetics of TiC coatings on AISI D3 steel produced by thermo-reactive diffusion technique. Pract Metallogr 2014; 51:95-106.

[17] Oliveira C.K.N, Muñoz Riofano R.M, L. Casteletti C. Formation of carbide layers on AISI H13 and D2 steels by treatment in molten borax containing dissolved both Fe-Nb and Fe-Ti powders. Mater Lett 2005; 59:14-15:1719-1722.

[18] Soltani R, Sohi M.H, Ansari M, Haghighi A, Haftlang F. Evaluation of niobium carbide coatings produced on AISI L2 steel via thermo-reactive diffusion technique. Vacuum 2017; 146: 44-51.

[19] De Damborenea J. Surface modification of metals by high power lasers. Surf Coat Technol 1998; 100: 377-382.

[20] Sen U. Friction and wear properties of thermo-reactive diffusion coatings against titanium nitride coated steels. Mater and Design 2005; 26(2): 167-174. 